\title{
Substituição do milho em grão por farelo de glúten de milho na ração de vacas em lactação em confinamento ${ }^{1}$
}

\author{
Alexandre Mendonça Pedroso², Flávio Augusto Portela Santos², Carla Maris Machado Bittar² \\ 1 Pesquisa financiada pela Fundação de Apoio à Pesquisa do Estado de São Paulo (FAPESP). \\ 2 Departamento de Zootecnia - Escola Superior de Agricultura "Luiz de Queiroz" - ESALQ/USP.
}

\begin{abstract}
RESUMO - Avaliou-se a substituição do milho moído por farelo de glúten de milho (FGM-21) para vacas em lactação alimentadas com ração completa contendo silagem de milho como volumoso principal e polpa cítrica como parte da fonte energética. Trinta vacas holandesas no terço médio de lactação foram mantidas em delineamento quadrado latino $3 \times 3$, composto de 10 quadrados simultâneos, e alimentadas com três rações completas: sem FGM-21 e com 20\% de milho na matéria seca (MS); 10\% de FGM-21 e 10\% de milho moído na MS; e 20\% de FGM-21 na MS e sem milho moído. As variáveis analisadas foram: consumo de matéria seca, produção e composição do leite, concentração de nitrogênio ureico no leite, parâmetros sanguíneos e escore de condição corporal das vacas. Os animais foram dispostos em 10 quadrados latinos $3 \times 3$, de acordo com a produção de leite, os dias em lactação e a paridade. A ingestão de MS (21,19 kg/dia), a produção de leite (24,88 kg/dia), a produção de leite corrigida para 3,5\% de gordura (25,34 kg/dia), o teor de gordura (3,62\%) e o teor de sólidos totais (11,86\%) não foram afetados pela substituição do milho moído por farelo de glúten de milho. A inclusão do farelo de glúten de milho afetou os teores de proteína e lactose do leite e a concentração de nitrogênio ureico do leite.
\end{abstract}

Palavras-chave: produção e composição do leite, resíduos fibrosos, ruminantes, subprodutos, vacas em lactação

\section{Replacing corn grain with corn gluten feed in the diet of feedlot lactating cows}

\begin{abstract}
Thirty mid lactating Holstein cows (159 DIM) were used to evaluate the substitution of ground corn with gluten feed (FGM-21) in total mixed diets containing corn silage as the main forage and citrus pulp as part of the energy source. Treatments were: no FGM-21 and 20\% ground corn in total feed DM (FGM 0), 10\% FGM-21 and $10 \%$ ground corn in total feed DM (FGM 10), and no corn and 20\% FGM-21 in total feed DM (FGM 20). The parameters evaluated were: dry matter intake, milk yield and composition, milk urea $\mathrm{N}$ concentration, blood parameters and body condition score. Cows were randomly assigned in ten $3 \times 3$ Latin Squares, according to milk yield, days in lactation and parity. Treatments did not affect the daily dry matter intake (DMI) $(21.19 \mathrm{~kg} / \mathrm{d})$, milk yield (24.88 kg/d), FCM yield $(25.34 \mathrm{~kg} / \mathrm{d})$, milk fat content $(3.62 \%)$, and milk total solids $(11.86 \%)$. Inclusion of corn gluten feed affected milk protein, lactose and urea concentrations.
\end{abstract}

Key Words: byproducts, fibrous feeds, lactating cows, milk production and composition, ruminants

\section{Introdução}

A crescente demanda pela utilização racional e sustentável dos recursos alimentícios em todo o mundo tem exercido pressão cada vez maior sobre a necessidade de se pesquisar a utilização de fontes alimentícias alternativas na nutrição animal que não causem competição por alimentos usados em larga escala na alimentação humana. Nesse contexto, a busca por alternativas para substituir os grãos de cereais na alimentação de ruminantes assume grande importância.

Além disso, o custo dessas fontes tradicionais de alimento tem se tornado limitante à rentabilidade dos sistemas de produção animal, e a inclusão de fontes energéticas alternativas em rações para vacas em lactação tem como principal objetivo baixar os custos de alimentação, mantendo os níveis de produção de leite.

Outro benefício da inclusão de subprodutos pode ser a redução no teor de amido das rações, com concomitante aumento nos teores de fibra digestível, contribuindo para melhoria do ambiente ruminal (Santos et al., 2005). Entre as várias possibilidades, o farelo de glúten de milho (FGM-21) constitui alternativa interessante para substituir, ao menos em parte, o milho em grão nas rações para vacas em lactação. Segundo Firkins et al. (1985), o valor energético do FGM-21 é equivalente a 92-95\% do milho. No entanto, em muitos 
trabalhos onde o subproduto substitui os grãos de milho em rações para vacas em lactação, não se verificou prejuízo ao desempenho dos animais.

Fellner \& Belyea (1991) afirmaram que, em virtude de suas características bromatológicas, o FGM-21 constitui ótima alternativa para inclusão em rações à basea de grãos e silagem de milho. A maioria dos trabalhos em que se comparou a substituição do milho por ingredientes alternativos foi realizada nos EUA utilizando-se como volumoso feno ou silagem pré-secada de alfafa e silagem de milho de alta qualidade. No entanto, os resultados obtidos com a utilização de volumosos com características diferentes podem não ser os mesmos. Além disso, na quase totalidade dos trabalhos revisados, em que se estudou a substituição do milho por FGM-21, as rações controle continham elevados teores de milho e não continham outros subprodutos energéticos como a polpa cítrica.

Objetivou-se avaliar a utilização do FGM-21 em condições semelhantes às encontradas em fazendas do Sudeste brasileiro, nas quais a combinação de milho e polpa cítrica tem sido utilizada para substituir o uso exclusivo de milho como principal suplemento energético das rações. Estudou-se a inclusão de três teores de farelo de glúten de milho (FGM-21: 0, 10 e 20\% da MS total) em substituição parcial ou total ao milho moído em rações contendo polpa cítrica e seus efeitos sobre a produção e composição do leite, o consumo de matéria seca e as variáveis sanguíneas.

\section{Material e Métodos}

O experimento foi conduzido nas instalações do Departamento de Zootecnia da Escola Superior de Agricultura “Luiz de Queiroz” - Universidade de São Paulo (ESALQ/ USP), em Piracicaba, São Paulo, entre os meses de fevereiro e março de 2003. As instalações constaram de um sistema de confinamento do tipo free-stall com três divisórias com 14 baias. Foram utilizadas 30 vacas da raça Holandesa, com período médio de lactação de $159( \pm 23,2)$ dias e produção média de leite de $24,5( \pm 4,1) \mathrm{kg} / \mathrm{dia}$. Todos os animais receberam injeções de somatotropina bovina recombinante (Lactotropin ${ }^{\circledR}$ ) a cada 10 dias.

Avaliaram-se três níveis de substituição do milho moído por farelo de glúten de milho (FGM-21) na ração completa: sem FGM-21 e com 20\% de milho na MS; $10 \%$ de FGM-21 e 10\% de milho moído na MS; e 20\% de FGM-21 na MS, sem milho moído (FGM 20).

As rações foram formuladas conforme o NRC (2001) para serem isoproteicas e continham silagem de milho como volumoso basal. Os ingredientes utilizados foram silagem de milho, feno de gramínea, milho moído fino, polpa cítrica peletizada, FGM-21, farelo de algodão, ureia, suplemento mineral e vitamínico e bicarbonato de sódio (Tabela 1). Como ao longo de experimento foram utilizadas diferentes partidas de milho, polpa cítrica e farelo de algodão, houve diferença na composição das rações experimentais em relação às rações formuladas, bem como ligeira variação nos teores de PB entre as rações experimentais. O teor de FDN das rações foi superior ao planejado, em decorrência da falta de chuvas na área de produção do milho, o que prejudicou a granação das espigas e o conteúdo de FDN da silagem de milho.

O período pré-experimental teve duração de 14 dias, durante o qual todas as vacas receberam a mesma ração. A produção de leite durante esse período, o estágio de lactação e a ordem de parição foram usados para compor os grupos de animais inerentes a cada quadrado latino. O período experimental teve duração de 42 dias, divididos em três subperíodos de 14 dias. Os primeiros 11 dias de cada subperíodo foram destinados à adaptação dos animais às rações e os outros 3 às avaliações. Os animais foram pesados no início e ao final de cada período experimental.

Tabela 1 - Composição das rações experimentais

\begin{tabular}{|c|c|c|c|}
\hline \multirow{2}{*}{ Ingrediente, \% da MS } & \multicolumn{3}{|c|}{$\begin{array}{l}\text { Nível de farelo de glúten } \\
\text { de milho (\% da ração total })^{1}\end{array}$} \\
\hline & 0 & 10 & 20 \\
\hline Silagem de milho & 30,00 & 30,00 & 30,00 \\
\hline Feno de gramínea & 10,00 & 10,00 & 10,00 \\
\hline Milho moído fino & 20,00 & 10,00 & - \\
\hline FGM-21 & - & 10,00 & 20,00 \\
\hline Polpa cítrica & 17,46 & 18,76 & 20,07 \\
\hline Farelo de algodão & 18,28 & 17,45 & 16,58 \\
\hline Uréia & 0,87 & 0,44 & 0,00 \\
\hline Suplemento mineral-vitamínico ${ }^{1}$ & 2,65 & 2,65 & 2,65 \\
\hline Bicarbonato de sódio & 0,70 & 0,70 & 0,70 \\
\hline Composição química & & & \\
\hline Matéria seca, \% & 55,91 & 55,85 & 55,80 \\
\hline Proteína bruta, \% da $\mathrm{MS}^{2}$ & 17,30 & 17,40 & 17,50 \\
\hline $\begin{array}{l}\text { Fibra em detergente neutro, } \\
\% \text { da } \mathrm{MS}^{2}\end{array}$ & 41,10 & 44,70 & 48,30 \\
\hline $\begin{array}{l}\text { Fibra em detergente neutro } \\
\text { forragem, } \% \text { da } \mathrm{MS}^{2}\end{array}$ & 27,00 & 27,00 & 27,00 \\
\hline $\begin{array}{l}\text { Carboidratos não-fibrosos, } \\
\% \text { da } \mathrm{MS}^{2}\end{array}$ & 35,50 & 31,80 & 28,00 \\
\hline Amido, \% da $\mathrm{MS}^{2}$ & 20,17 & 13,80 & 7,46 \\
\hline Extrato etéreo, \% da $\mathrm{MS}^{2}$ & 2,30 & 2,10 & 1,90 \\
\hline $\begin{array}{l}\text { Nutrientes digestíveis totais, } \\
\% \text { da } \mathrm{MS}^{3}\end{array}$ & 66,83 & 65,44 & 64,03 \\
\hline $\mathrm{EL}_{\mathrm{L}}, \mathrm{Mcal} / \mathrm{kg} \mathrm{MS}^{3}$ & 1,50 & 1,49 & 1,49 \\
\hline
\end{tabular}

${ }^{1}$ Composição do suplemento mineral-vitamínico: Ca, 16,81\%; P, 4,20\%; S, 2,29\%; Na, 11,56\%; Cl, 8,06\%; Mg, 2,67\%; Co, 38,2 ppm; Cu, 343,83 ppm; I, 30,58 ppm; Fe, 578,94 ppm; Mn, 1146,15 ppm; Se, 15,30 ppm; Zn, 1184,20 ppm; vit. A $68.760 \mathrm{UI} / \mathrm{kg}$; vit. $\mathrm{D}_{3}$ : $57.300 \mathrm{UI} / \mathrm{kg}$; vit. E, $764 \mathrm{UI} / \mathrm{kg}$; Rumensin, 0,60\%.

${ }^{2}$ Valores obtidos com base nos resultados das análises químicas dos ingredientes.

${ }^{3}$ Valores estimados de acordo com NRC (2001). 
As vacas foram ordenhadas duas vezes ao dia, às $6 \mathrm{~h}$ e $18 \mathrm{~h}$, e as produções de leite individuais registradas nos últimos três dias de cada subperíodo, por meio de medidores do tipo "Mark V". Amostras de leite de cada vaca foram obtidas também nesses dias, na ordenha da tarde, e analisadas quanto aos teores de gordura, proteína, lactose e sólidos totais pelo processo de infravermelho pelo analisador Bentley 2000 (Bentley Instruments ${ }^{\circledR}$ ) e nitrogênio ureico pelo analisador ChemSpec 150 (Bentley Instruments ${ }^{\circledR}$ ), no Laboratório da Clínica do Leite do Departamento de Zootecnia da ESALQ/USP.

Os animais foram alimentados duas vezes ao dia, às $6 \mathrm{~h}$ e $18 \mathrm{~h}$, e as sobras de alimento foram pesadas e descartadas diariamente antes do fornecimento do período da tarde. O consumo de alimento foi medido diariamente em grupo, por tratamento, durante os últimos três dias de colheita de dados de cada subperíodo.

A silagem foi amostrada semanalmente e os outros alimentos no início de cada período de coleta de dados. As amostras de silagem foram armazenadas a $-18^{\circ} \mathrm{C}$ e subamostras da silagem foram secas imediatamente após a amostragem, a $105^{\circ} \mathrm{C}$ por 24 horas, para quantificação da MS, a fim de se proceder ao ajuste da formulação das rações. Após o período experimental, as amostras foram secas a $55^{\circ} \mathrm{C}$ (em estufa com circulação forçada de ar por 72 horas) e analisadas quanto aos teores de MS (3 horas em estufa a $105^{\circ} \mathrm{C}$ ), matéria orgânica (MO) (3 horas em mufla a $600^{\circ} \mathrm{C}$ ), FDN, de acordo com Van Soest et al. (1991), FDA, de acordo com Van Soest (1973), proteína bruta (PB) de acordo com AOAC (1990), e amido, segundo método descrito por Poore et al. (1993).

No último dia de cada subperíodo, 4 horas após alimentação, amostras de sangue foram colhidas da veia coccígea utilizando-se tubos providos de vácuo, contendo antiglicolítico e anticoagulante. As amostras foram centrifugadas em $2.000 \mathrm{~g}$ por 20 minutos e armazenadas a $-18^{\circ} \mathrm{C}$ para posterior quantificação das concentrações de glicose pelo Analisador Bioquímico YSI 2700S (Yellow Springs Instrument Co. Inc., Ohio, USA).

O delineamento estatístico utilizado foi o quadrado latino $3 \times 3$, com agrupamento de dez quadrados simultâneos.

Os dados de consumo foram analisados como quadrados latinos simples, de modo que cada lote de animais de cada tratamento foi considerado unidade experimental, uma vez que o consumo de alimento foi medido em grupo e não individualmente.

Os dados foram analisados pelo PROC GLM (General Linear Models) do programa estatístico SAS (2000), versão 8.2 para Windows. Foi feita a análise de regressão polinomial de $1^{\underline{0}}$ e $2 \underline{0}$ graus considerando o nível de significância de $5 \%$ para a probabilidade do teste $\mathrm{F}$ na análise de variância.

Todos os dados foram testados para se verificar a distribuição normal dos erros, utilizando-se o PROC UNIVARIATE (SAS 2000). Os dados que apresentaram erros fora do intervalo entre \pm 3 desvios foram descartados da análise estatística.

\section{Resultados e Discussão}

O consumo de matéria seca foi, em média, de 21,3 kg/ vaca $\times$ dia, valor elevado para o nível de produção observado, de 24,9 kg leite/dia, característico de vacas na segunda metade da lactação (Tabela 2).

Não se observou diferença significativa $(\mathrm{P}>0,05)$ no consumo de matéria seca entre os níveis de farelo de glúten de milho (Tabela 2), o que está de acordo com diversos trabalhos e revisões da literatura (Armentano \& Dentine, 1988; Bernard et al., 1991; Gunderson et al., 1988). No entanto, em alguns trabalhos, houve aumento no consumo de matéria seca com a inclusão do FGM-21 em rações para vacas em lactação (Blasi et al., 2001; DeLost et al., 1989; Firkins et al., 1991; Fleck et al., 1988; Hannah et al., 1990; Kononoff et al., 2006; McLeod et al., 2001; Vanbaale et al., 1999), o que pode ser explicado pelo aumento na taxa de passagem ou na digestibilidade das rações com o subproduto. No entanto, na maior parte desses trabalhos revisados, o FGM-21 substituiu parte do volumoso. Em geral, os dados disponíveis acerca dos efeitos do FGM-21 sobre o consumo de MS em vacas em lactação são pouco conclusivos.

Em geral, os valores de FDN do farelo de glúten de milho são mais altos que os de alimentos concentrados tradicionais. Embora a concentração de FDN esteja relacionada à ingestão de matéria seca - de modo que valores altos de FDN na ração possam limitar o consumo -, isto não deve ocorrer caso a FDN seja proveniente de FGM-21, uma vez que sua fibra é caracterizada por rápida e extensa degradabilidade. Prova disso é o fato de vacas em lactação aparentemente compensarem com aumento de consumo os menores valores de energia líquida para lactação $\left(E L_{L}\right)$ de rações à base de FGM-21 em comparação a rações à base de milho em grãos, resultando em consumos de 1,5 a 1,8 kg de FDN/100 kg de peso vivo, superior aos valores obtidos quando a FDN é em sua maioria proveniente de forragem (Fellner \& Belyea, 1991).

Neste trabalho, a produção de leite não foi afetada pelos níveis de farelo de glúten de milho ( $\mathrm{P}>0,05)$. $\mathrm{Na}$ literatura há trabalhos que descrevem aumento na produção de leite com a utilização desse subproduto (Blasi et al., 2001; 
Tabela 2 - Consumo de matéria seca, produção e composição do leite, concentração de nitrogênio ureico no leite e concentração de glicose plasmática

\begin{tabular}{|c|c|c|c|c|c|c|}
\hline Variável $^{1}$ & \multicolumn{3}{|c|}{ Nível de glúten de milho (\% da ração total) ${ }^{2}$} & $\mathrm{EPM}^{3}$ & \multicolumn{2}{|c|}{$\mathrm{P}^{4}$} \\
\hline Leite (kg/dia) & 25.17 & 24,91 & 24,55 & 0,030 & NS & NS \\
\hline Consumo de matéria seca (kg MS/animal×dia) & 21,03 & 22,32 & 20,22 & 0,820 & NS & NS \\
\hline Gordura $(\%)$ & 3,52 & 3,60 & 3,74 & 0,076 & NS & NS \\
\hline Gordura (kg/dia) & 0,88 & 0,88 & 0,91 & 0,022 & NS & NS \\
\hline Relação gordura/proteína & 1,16 & 1,20 & 1,26 & 0,025 & 0,009 & NS \\
\hline Lactose $(\%)$ & 4,40 & 4,34 & 4,35 & 0,011 & 0,002 & 0,019 \\
\hline Lactose (kg/dia) & 1,11 & 1,09 & 1,08 & 0,014 & NS & NS \\
\hline Sólidos totais (\%) & 11,85 & 11,82 & 11,92 & 0,075 & NS & NS \\
\hline Sólidos totais (kg/dia) & 2,98 & 2,94 & 2,92 & 0,040 & NS & NS \\
\hline Nitrogênio ureico do leite (mg/dL) & 13,55 & 13,04 & 13,67 & 0,190 & NS & 0,024 \\
\hline
\end{tabular}

${ }^{1}$ LCG 3,5 = produção de leite corrigida para 3,5\% de gordura.

2 FGM 0 = sem FGM-21 e 20\% de milho na MS da ração completa; FGM 10 = 10\% de FGM-21 e 10\% de milho moído na MS da ração completa; FGM 20 = 20\% de FGM-21 na MS da ração completa e sem milho moído.

3 EPM = erro-padrão da média.

${ }^{4}$ Probabilidade dos contrastes para (L) efeito linear e $(\mathrm{Q})$ efeito quadrático (desvio da linearidade) para os teores de FGM-21 testados; NS = não-significativo.

Firkins et al., 1991; Kononoff et al., 2006). Nesses casos também houve acréscimo no consumo de matéria seca e o aumento na produção de leite pode ser creditado à maior ingestão de alimentos e não necessariamente à inclusão do FGM-21 nas rações.

Em outros trabalhos não houve efeitos do FGM-21 sobre a produção de leite (Armentano \& Dentine, 1988; Gunderson et al., 1988; DeLost et al., 1989; Bernard et al., 1991; Bernard \& Mcneill, 1991; Ferdinand et al., 2001; Schroeder, 2003), apesar de as rações com altos níveis de FGM-21 apresentarem menor valor energético em comparação a rações tradicionais, com alta porcentagem de grãos de cereais. Neste ensaio, os valores de $\mathrm{EL}_{\mathrm{L}}$ praticamente não diferiram entre os níveis de farelo de glúten de milho, mas a concentração de NDT diminuiu com a inclusão do FGM-21 (Tabela 1) e, mesmo assim, a produção de leite se manteve, o que está de acordo com os trabalhos supracitados.

Não houve efeito dos níveis de farelo de glúten de milho sobre o teor de gordura do leite, nem sobre a produção total de gordura, mesmo com a maior concentração de FDN e a menor concentração de amido nas rações com o subproduto. Rações com maior concentração de fibra fisicamente efetiva estimulam mais a ruminação que rações ricas em CNF e com menor teor de FDN, o que sabidamente está associado ao aumento no teor de gordura do leite. Mesmo assim esse padrão não foi observado neste trabalho.

De modo geral, os dados da literatura permitem evidenciar pouca variação na composição do leite com a utilização do FGM-21 em rações para vacas em lactação. Além disso, na interpretação dos resultados, há muita variação entre as rações experimentais e o FGM-21 substitui, ora parte do volumoso, ora parte do concentrado e, em muitos casos, parte de ambos. Blasi et al. (2001) revisaram 11 trabalhos com 23 tratamentos diferentes nos quais o FGM-21 perfazia 12 a $60 \%$ da MS total das rações e concluíram que os efeitos da inclusão do subproduto sobre a produção e composição do leite geralmente são pequenos.

Em trabalho recente, Kononoff et al.(2006) demonstraram redução no teor de gordura do leite quando o FGM-21 substituiu parte do volumoso e parte do concentrado. No entanto, como nesse trabalho houve aumento na produção de leite com a inclusão do subproduto, não houve diferenças na síntese total de gordura no leite. Respostas similares foram obtidas por Boddugari et al. (2001) e Wickershm et al. (2004). Vanbaale et al. (2001), por sua vez, observaram que a substituição de parte do volumoso e parte do concentrado pelo FGM-21 não alterou o teor de gordura, mas resultou em maior síntese de gordura no leite, uma vez que a produção de leite foi maior nos animais alimentados com a ração que continha o subproduto.

Os dados obtidos neste trabalho indicam que a substituição do milho moído pelo FGM-21 teve efeito quadrático sobre o teor de proteína e efeito linear sobre a produção total de proteína do leite e as rações que continham o subproduto promoveram valores significativamente menores que os da ração controle. Esse resultado difere de boa parte dos dados disponíveis na literatura (Alves et al., 2005; Blasi et al., 2001; Kononoff et al., 2006; Schroeder, 2003; Vanbaale et al., 2001; Wickersham et al., 2004), que não indicam alterações na proteína do leite com a inclusão 
do FGM-21 às rações de vacas leiteiras. No entanto, nesses trabalhos o subproduto substituiu parte do concentrado e parte da forragem.

Em trabalho com substituição apenas do concentrado pelo FGM-21, Boddugari et al. (2001) observaram redução no teor de proteína e síntese de proteína no leite, mas o nível do subproduto nas rações experimentais nesse trabalho foi superior ao utilizado nesta pesquisa, chegando a $45 \%$ da MS total. No nível mais baixo, 21,9\% da MS, não houve diferenças no teor de proteína do leite. Os autores creditaram a redução no teor e na síntese de proteína do leite ao menor consumo de MS observado com o aumento no teor de FGM-21 nas rações e à menor disponibilidade de proteína metabolizável, especialmente para a ração com o maior nível do subproduto.

Os dados obtidos podem refletir falta de energia para melhorar a síntese de proteína microbiana no rúmen com as rações contendo FGM-21, o que reduziria a disponibilidade de proteína metabolizável no intestino delgado e teria reflexos negativos na síntese de proteínas na glândula mamária. Isso é coerente com o menor teor de amido e NDT dessas rações.

As variações nos teores de proteína e gordura do leite ocasionaram aumento linear no valor da relação gordura/ proteína do leite com a inclusão do FGM-21 nas rações.

A substituição do milho moído pelo FGM-21 também reduziu de forma quadrática o teor de lactose do leite. Apesar disso, a síntese total de lactose não variou significativamente entre os níveis de FGM-21. Da mesma forma que para a proteína do leite, na maioria dos trabalhos revisados, não se observou alteração nos teores de lactose do leite (Blasi et al., 2001; Vanbaale et al., 2001; Schroeder, 2003; Alves et al., 2005; Kononoff et al., 2006). De maneira contrária, Wickersham et al., (2004) verificaram aumento no teor de lactose do leite com a inclusão do FGM-21 em substituição a parte do concentrado e parte do volumoso. A redução no teor de lactose observada nesta pesquisa pode estar relacionada à menor disponibilidade energética proporcionada pelas rações com o subproduto, o que reduziria o aporte de glicose para a glândula mamária, prejudicando a síntese de lactose.

A concentração total de sólidos no leite não apresentou variação entre os níveis de FGM-21, o que está de acordo com a maior parte dos trabalhos revisados (Alves et al., 2005; Blasi et al., 2001; Kononoff et al., 2006; Vanbaale et al., 2001). Schroeder (2003) mostrou aumento linear neste parâmetro com o aumento no teor de FGM-21 nas rações, entre 0 e 45\% da MS total. Como o FGM-21 substituiu parte do concentrado e parte do volumoso, é possível que tenha havido maior disponibilidade de nutrientes para síntese de compo- nentes do leite nas rações com o FGM-21. De fato, as rações com o subproduto continham teor de PB mais elevado que o da ração controle, mas as rações foram formuladas para conter concentrações energéticas equivalentes.

Observou-se efeito quadrático dos níveis de farelo de glúten de milho sobre a concentração de nitrogênio ureico no leite (NUL) e a ração com $10 \%$ desse subproduto apresentou valores inferiores aos demais. Os valores observados para essa variável são condizentes com as características das rações experimentais, especialmente quanto ao teor de PB (17,4\% em média), e são mais baixos que os observados por Schroeder (2003), Vanbaale et al. (2001) e Wickersham et al. (2004). Nos trabalhos de Schroeder (2003) e Wickersham et al. (2004), os teores de PB das rações experimentais ficaram em torno de 18,5\%, o que pode explicar a maior concentração de NUL. Entretanto, no trabalho de Vanbaale et al. (2001), a ração controle e aquela com 20\% de FGM-21 na MS apresentaram, respectivamente, 16,7 e 17,3\% de PB na MS e, mesmo assim, os valores de NUL foram equivalentes a 16,07 e $15,64 \mathrm{mg} / \mathrm{dL}$, respectivamente. Conforme destacado por Imaizumi (2005), o N-ureico no leite reflete o teor e a degradabilidade da PB da ração, bem como a qualidade dessa proteína. No trabalho de Vanbaale et al. (2001), foram utilizados feno de alfafa e caroço de algodão, e as características da fração proteica dessas rações podem explicar os valores mais elevados de NUL.

A concentração plasmática de glicose foi, em média, de 48,45 mg/dL, e não diferiu entre os níveis de farelo de glúten de milho, mantendo-se na faixa de variação considerada normal, entre 42 e 74 mg/dL para vacas em lactação (Fraser, 1991).

\section{Conclusões}

A substituição do milho em grãos por farelo de glúten de milho não causa alterações na produção de leite, mas resulta em poucas e discretas variações na composição do leite. Dessa forma, o uso desse subproduto como substituto do milho em rações para vacas leiteiras produzindo em torno de $25 \mathrm{~kg}$ de leite ao dia pode ser interessante, desde que seu preço seja melhor que o do cereal.

\section{Literatura Citada}

ALVES, A.C.N.; MATTOS, W.; SANTOS, F.A.P. et al. Composição e produção de leite de vacas holandesas alimentadas com farelo de glúten de milho desidratado em substituição parcial à silagem de milho. In: REUNIÃO ANUAL DA SOCIEDADE BRASILEIRA DE ZOOTECNIA, 42., 2005, Goiânia. Anais... Goiânia: Sociedade Brasileira de Zootecnia, [2005]. (CD-ROM). 
ARMENTANO, L.E.; DENTINE, M.R. Wet corn gluten feed as a supplement for lactating dairy cattle and growing heifers. Journal of Dairy Science, v.71, n.4, p.990-995, 1988.

ASSOCIATION OF OFFICIAL ANALYTICAL CHEMISTS - AOAC. Official methods of analysis. 15.ed. Arlington: 1990. v.1, 1117p.

BERNARD, J.K.; DeLOST, R.C.; MUELLER, F.J. et al. Effect of wet or dry corn gluten feed on nutrient digestibility and milk yield and composition. Journal of Dairy Science, v.74, n.11, p.3913-3919, 1991.

BERNARD, J.K.; MCNEILL, W.W. Effect of high fiber energy supplements on nutrient digestibility and milk production of lactating dairy cows. Journal of Dairy Science, v.74, n.3, p.991-995, 1991.

BLASI, D.A.; BROUK, M.J.; DROUILLARD, J.S. et al. Corn gluten feed, composition and feeding value for beef and dairy cattle. Manhattan: Kansas State University Agricultural Experimental Station and Cooperative Extension, 2001. 14p. (Bulletin MF, 2488).

BODDUGARI, K.; GRANT, R. J.; STOCK, R. et al. Maximal replacement of forage and concentrate with a new wet corn milling product for lactating dairy cows. Journal of Dairy Science, v.84, n.4, p.873-884, 2001.

DeLOST, R.C.; MILLER, J.K. ; MULLER, F.J. et al. Performance of lactating dairy cows fed wet or dry corn gluten feed. Journal of Animal Science, v.72, p.511-512, 1989 (suppl. 1).

FELLNER. V.; BELYEA, R.L. Maximizing gluten feed in corn silage diets for cows. Journal of Dairy Science, v.74, n.3, p.996-1005, 1991.

FERDINAND, E.E.; SHIRLEY, J.E.; TITGEMEYER, E.C. et al. Performance of Holstein cows fed wet corn gluten feed or soyhull-steep liquor pellets during early lactation (Dairy Day). Manhattan: Kansas State University Agricultural Experiment Station and Cooperative Extension Service, 2001. p.44-46. (Report of Progress, 881).

FIRKINS, J.L.; BERGER, L.L.; FAHEY JR., G.C. Evaluation of wet and dry distillers grains and dry corn gluten feeds for ruminants. Journal of Animal Science, v.60, n.3, p.847-860, 1985.

FIRKINS, J.L.; EASTRIDGE, M.L.; PALMQUIST, D.L. Replacement of corn silage with dry corn gluten feed (FGM-21) and sodium bicarbonate (SB) for lactating dairy cows. Journal of Dairy Science, v.74, n.6, p.1944-1952, 1991.

FLECK, A.T.; LUSBY, K.S.; OWENS, F.N. et al. Effects of corn gluten feed on forage intake, digestibility and ruminal parameters of cattle fed native grass hay. Journal of Animal Science, v.66, n.3, p.750-757, 1988.

FRASER, C.M. Manual Merck de veterinária. 6.ed. São Paulo: Roca, 1991. 2169p.

GUNDERSON, S.L.; AGUILAR, A.A.; JOHNSON, D.E. et al. Nutritional value of wet corn gluten feed for sheep and lactating dairy cows. Journal of Dairy Science, v.71, n.5, p.1204-1210, 1988.

HANNAH, S.M.; PATERSON, J.A.; WILLIAMS, J.S. et al. Effects of corn vs corn gluten feed on site, extent and ruminal rate of forage digestion and rate and efficiency of gain. Journal of Animal Science, v.68, n.8, p.2536-2545, 1990.

IMAIZUMI, H. Suplementação protéica, uso de subprodutos agroindustriais e processamento de milho em rações para vacas leiteiras em confinamento. 2005. 182f. Tese (Doutorado em Ciência Animal e Pastagens) - Escola Superior de Agricultura “Luiz de Queiroz”/Universidade de São Paulo, Piracicaba, 2005.

KONONOFF, P.J.; IVAN, S.K.; MATZKE, W. et al. Milk production of dairy cows fed wet corn gluten feed during the dry period and lactation. Journal of Dairy Science, v.89, n.7, p.2608-2617, 2006.

McLEOD, G.K.; DROPPO, T.E.; GRIEVE, D.G. et al. Feeding value of wet corn gluten feed for lactating dairy cows. Canadian Journal of Animal Science, v.65, p.125-135, 2001.

NATIONAL RESEARCH COUNCIL - NRC. Nutrient requirements of dairy cattle. 7.rev.ed. Washington, D.C.: National Academy Press, 2001. 381p.

POORE, M.H.; MOORE, J.A.; SWINGLE, R.S. et al. Effect of fiber source and ruminal starch degradability on site and extent of digestion in dairy cows. Journal of Dairy Science, v.76, p.2244, 1993.

SANTOS, F.A.P.; PEDROSO, A.M.; MARTINEZ, J.C. et al. Utilização da suplementação com concentrados para vacas em lactação mantidas em pastagens tropicais. In: SIMPÓSIO SOBRE BOVinOCUltura Leiteira, 5., 2005, Piracicaba. Anais... Piracicaba: Fundação de Estudos Agrários "Luiz de Queiroz", 2005. p.219-294.

SCHROEDER, J.W. Optmizing the level of wet corn gluten feed in the diet of lactating dairy cows. Journal of Dairy Science, v.86, n.3, p.844-851, 2003.

STATISTICAL ANALYSIS SYSTEM - SAS. User's guide: statistics. Cary: 2000. 965p.

VANBAALE, M.J.; SHIRLEY, J.E.; SCHEFFEL, M.V. et al. Evaluation of wet corn gluten feed as an ingredient in diets for lactating dairy cows (Dairy Day). Manhattan: Kansas State University Agricultural Experiment Station and Cooperative Extension Service, 1999. p.17-18. (Report of Progress, 842).

VANBAALE, M.J.; SHIRLEY, J.E.; TITGEMEYER, E.C. et al. Evaluation of wet corn gluten feed in diets for lactating dairy cows. Journal of Dairy Science, v.84, n.11, p.2478-2485, 2001.

Van SOEST, P.J. Collaborative study of acid detergent fiber and lignin. Journal of the Association of Official Analytical Chemists, v.56, n.4, p.781-784, 1973.

Van SOEST, P.J.; ROBERTSON, J.B.; LEWIS, B.A. Methods for dietary fiber, neutral detergent fiber, and nonstarch polysaccharides in relation to animal nutrition. Journal of Dairy Science, v.74, n.10, p.3583-3597, 1991 .

WICKERSHAM, E.E.; SHIRLEY, J.E.; TITGEMEYER, E.C. et al. Response of lactating dairy cows to diets containing wet corn gluten feed or a raw soybean hull-corn steep liquor pellet. Journal of Dairy Science, v.87, n.11, p.3899-3911, 2004. 